\title{
Screening for refractive errors in children: accuracy of the hand held refractor Retinomax to screen for astigmatism
}

\author{
Monique Cordonnier, Michèle Dramaix
}

\begin{abstract}
Aims-To assess the reliability of the hand held automated refractor Retinomax in measuring astigmatism in noncycloplegic conditions. To assess the accuracy of Retinomax in diagnosing abnormal astigmatism in non-cycloplegic refractive screening of children between 9 and 36 months.
\end{abstract}

Methods-Among 1205 children undergoing a non-cycloplegic refractive screening with Retinomax, 299 (25\%) had repeated non-cycloplegic measurements, $302(25 \%)$ were refracted under cycloplegia using the same refractor, and $88(7 \%)$ using retinoscopy or an automated on table refractor. The reproducibility of non-cycloplegic cylinder measurement was assessed by comparing the cylindrical power and axis values in the 299 repeated measurements without cycloplegia. The influence of the quick mode on cylinder measurement was analysed by comparing the cylinder and axis value in 93 repeated measurements without cycloplegia where normal mode was used in one measurement and quick mode in the other. Predictive values of the refractive screening were calculated for three different thresholds of manifest astigmatism ( $\geqslant 1.5, \geqslant 1.75$, and $\geqslant 2 D)$ considering as a true positive case an astigmatism $\geqslant 2 \mathrm{D}$ under cycloplegic condition (measured by retinoscopy, on table, or hand held refractor).

Results-The 95\% limits of agreement between two repeated manifest cylinder measurements with Retinomax attained levels slightly less than plus or minus $1 \mathrm{D}$. The $95 \%$ limits of agreement for the axis were plus or minus $46^{\circ}$. The comparison of non-cycloplegic measurements in the quick and normal mode showed no significant difference and $95 \%$ limits of agreement plus or minus $0.75 \mathrm{D}$. The mean difference between non-cycloplegic and cycloplegic cylinder values measured by Retinomax reached $0.17 \mathrm{D}$ and was statistically significant. Manifest thresholds of $\geqslant 1.5 \mathrm{D}, \geqslant 1.75 \mathrm{D}, \geqslant 2 \mathrm{D}$ cylinder value diagnosed $2 \mathrm{D}$ of astigmatism under cycloplegia respectively with $71-84 \%$, 59$80 \%, 51-54 \%$ of sensitivity (right eye-left eye) and $90-92 \%, 95 \%, 98 \%$ of specificity.

Conclusion-Without cycloplegia, Retinomax is able to measure cylinder power with the same reproducibility as cycloplegic retinoscopy. No significant difference was found in the cylinder values obtained with the quick and the normal modes. Therefore, the quick mode of measurement is recommended as it is more feasible in children. No difference, which is significant from a screening point of view, exists between the non-cycloplegic and the cycloplegic cylinder value $(<0.25$ D). Retinomax diagnoses abnormal astigmatism ( $\geqslant 2 \mathrm{D})$ in a non-cycloplegic refractive screening at preschool ages with $51-84 \%$ sensitivity rates and $98-90 \%$ specificity rates, depending on the chosen threshold of manifest astigmatism. If $2 \mathrm{D}$ of manifest astigmatism is chosen as a positive test, the positive predictive value of the screening reaches $81-84 \%$ and the negative predictive value $91-90 \%$ (right eye-left eye).

(Br F Ophthalmol 1999;83:157-161)

Astigmatism is common in the infant population. The incidence of astigmatism of $\geqslant 1 \mathrm{D}$ is around $50 \%$ in children under 12 months of age. ${ }^{1}$ During the first few years of life, the extent and incidence of astigmatism decline, mostly during the second year. ${ }^{1}$

Amblyopia can be the result of a significant uncorrected astigmatism. Gwiazda et $a l^{2}$ showed that meridional amblyopia can result from astigmatism in early childhood (second half of the first year to the end of the second year). Ingram et $a l^{3}$ found that children having 1.5 D or more of astigmatism at 1 year of age have a higher incidence of amblyopia at 3.5 years. Sjöstrand and Abrahamsson ${ }^{4}$ found that children with constant and increasing astigmatism are "at risk" of developing amblyopia: oblique astigmatism as well as increasing astigmatism associated with high hypermetropia $(\geqslant+3.5 \mathrm{D})$ presented the relatively higher risks. Atkinson et $a l^{5}$ found a strong relation between meridional amblyopia at 4 years of age and the persistence of astigmatism $\geqslant 1 \mathrm{D}$ after 2 years of age. This meridional amblyopia partly contributed to poor performance on the acuity tests at 4 years.

In their study, Friedburg and Kloppel $^{6}$ showed that early (under 4 years) correction of hypermetropic astigmatism $\geqslant 1 \mathrm{D}$ resulted in better development of visual acuity of the dominant eye in strabismic children measured at the age of 8 years or later. The proportions of good vision were even higher when the children were corrected under 2.5 years of age. It is therefore important in refractive screening to diagnose astigmatism adequately.
Accepted for publication 11 September 1998 
As we are involved in a non-cycloplegic refractive screening with the hand held refractor Retinomax, we wanted to test the reliability and accuracy of this refractor. We have already studied its ability to screen for high hyperopia ${ }^{7}$ and decided to further investigate its usefulness in screening for astigmatism.

\section{Material}

RETINOMAX HAND HELD REFRACTOR

This hand held refractor has been fully described elsewhere. ${ }^{78}$ In the normal mode, a fogging system aims to minimise accommodation. The quick mode disables the fogging system and speeds the measurement process which is helpful in very young children: only 10 seconds are needed to start measuring and obtain 16 data points for both eyes. It also allows easy repetition of measurements.

The width of the target (christmas tree on a green grass and blue sky background) is $2 \mathrm{~cm}$, the subject eye is situated $6 \mathrm{~cm}$ away from the target. If the subject does not look at the christmas tree but at either side of the target, this will induce a disparity of approximately $10^{\circ}$ between the fixation axis and the axis of autorefraction. According to Banks, ${ }^{9}$ this could induce a spurious astigmatism of 0.75 to $1.5 \mathrm{D}$ in children.

\section{Subjects and methods}

Since November 1995, we have organised free visual screening for children between 9 to 36 months at our university hospital situated in Brussels. Specifications concerning the screening have been described elsewhere. ${ }^{7}$ Among other tests, this visual screening required a measurement of manifest refraction with the Retinomax autorefractometer. If the child was reluctant and had to be forcibly steadied, care was taken not to push on his eye when opening the lids during the measurements to avoid artefactual astigmatism. In our tests, the success rate of measuring refraction with the hand held refractor in children of this age reached $98.5 \% .^{7}$ The $1.5 \%$ of children who could not be successfully refracted with the Retinomax were refracted by another method (Viva off axis binocular videorefraction, Tomey Inc) and were not included in this study.

Among the 1205 screened children, 20\% were screened positive because they had one or more criteria of abnormal manifest refraction (hyperopia $>1.5 \mathrm{D}$, myopia $>3 \mathrm{D}$, astigmatism $\geqslant 2 \mathrm{D}$, anisometropia $\geqslant 1.5 \mathrm{D}$ ) and/or a squint. These children were referred to an ophthalmologist outside the hospital (for deontological reasons, given the fact that the screening was free, no child attending the screening could be referred to an ophthalmologist appointed by the hospital). Before starting the screening, we established a list of ophthalmologists who were interested in treating children (61 ophthalmologists in Brussels area). If a child was screened positive, we gave this list to the parents, together with the result of the screening specifying the presence or absence of any squint, media opacity, or refractive anomaly. In case of a refractive defect, the manifest refraction measured by the Retin- omax was stated. The consulting ophthalmologist was asked to return to us a dated and signed feedback form specifying the cycloplegic refraction of the child and confirming the presence or absence of any squint or media opacity.

In our screening, the retained refractive value of one measurement corresponded to the isolated representative value of the eight collected data points for each eye, expressed in sphere, negative cylinder, and axis.

The use of normal or quick mode of Retinomax measurement was registered.

In a total of 1205 screened children, 906 children had one measurement only, 275 had two measurements, and 24 had three measurements without cycloplegia. Repeated measurements were taken during the same session and were performed by one of the authors (MC) or by the orthoptist in charge of the screening. We did not compare the results from different operators as the training and competence needed for using Retinomax is minimal.

We analysed the reproducibility between non-cycloplegic measurements applying the method described by Bland and Altman ${ }^{10}$ : in the 299 cases with two measurements or more, we determined the mean difference between them and the $95 \%$ limits of agreement of the three refractive components.

In order to establish whether the quick mode influences the measurement of astigmatism, we compared both modes of measurement without cycloplegia in 93 children.

Out of the 1205 children, 302 were also refracted with cycloplegia (three drops of cyclopentolate $0.5 \%$ in each eye at 5 minute intervals followed by measurement 40 minute later) during the same session, by the same operators as previously described, using the same hand held refractometer. These 302 children were selected on the sole criterion that the parents agreed to cycloplegia being performed. If the child was screened positive, the parents were told: "We suspect a visual defect in your child, do you agree if we confirm this defect by a further investigation that requires drops in the eyes of your child." If the child was screened negative, the parents were told "The visual screening does not show any defect in your child, and this can be double checked by a further investigation with drops if you wish."

Forty three per cent of these 302 children were screened positive because they had one or more criteria of abnormal manifest refraction (hyperopia $>1.5 \mathrm{D}$, myopia $>3 \mathrm{D}$, astigmatism $\geqslant 2 \mathrm{D}$, anisometropia $\geqslant 1.5 \mathrm{D}$ ) and/or a squint. The other $57 \%$ were screened negative.

We performed the analysis of agreement between the 302 non-cycloplegic and cycloplegic cylinder values measured by Retinomax.

Whenever non-cycloplegic measurements had been repeated, we chose the most positive representative value for the sphere and the least negative for the cylinder, in order to minimise accommodation.

Eighty eight (7\%) of these 1205 screened children had a cycloplegic refraction performed by an on table autorefractor (78 children) or by retinoscopy (10 children): they 

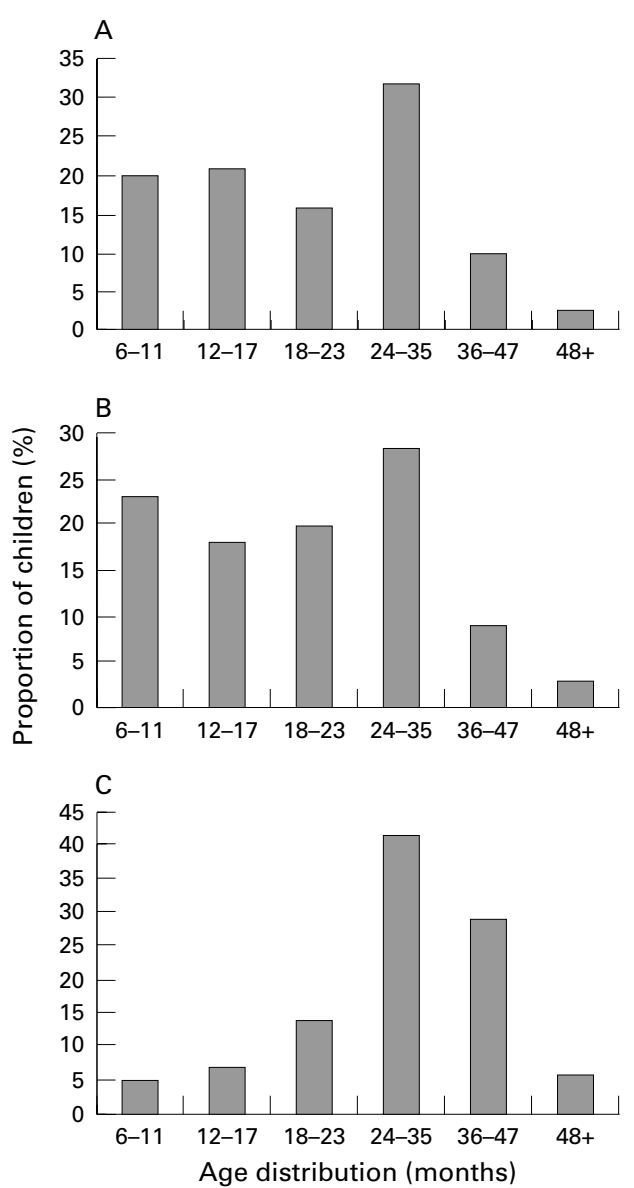

Figure 1 (A) Age distribution (months) of the 1205 screened children. (B) Age distribution (months) of the 302 children refracted by Retinomax with and without cycloplegia. (C) Age distribution (months) of the 88 children refracted by retinoscopy or on table refractor.

belonged to the $20 \%$ of children screened positive and the cycloplegic refraction was performed not more than 6 months later by the ophthalmologist to whom the child was referred. As our feedback ratio was only $40 \%$ and as some of the feedback forms were unworkable (the refraction was not specified, or not performed under cycloplegia, or the delay was too long between the screening and

Table 1 Reproducibility of non-cycloplegic Retinomax measurements

\begin{tabular}{|c|c|c|c|c|c|c|}
\hline & \multicolumn{2}{|c|}{ Sphere (D) } & \multicolumn{2}{|c|}{ Cylinder (D) } & \multicolumn{2}{|l|}{ Axis (อ) } \\
\hline & Right eye & Left eye & Right eye & Left eye & Right eye & Left eye \\
\hline $\begin{array}{l}\text { Number of pairs } \\
\mathrm{d} \\
95 \% \text { lim agreement } \\
\mathrm{p} \text { (paired } t \text { test) }\end{array}$ & $\begin{array}{l}294 \\
0.09 \\
+/-2.65 \\
\text { NS }\end{array}$ & $\begin{array}{l}292 \\
0.13 \\
+/-2.42 \\
\text { NS }\end{array}$ & $\begin{array}{l}294 \\
0.04 \\
+/-0.90 \\
\text { NS }\end{array}$ & $\begin{array}{l}292 \\
0.02 \\
+/-0.83 \\
\text { NS }\end{array}$ & $\begin{array}{l}246 \\
1.6 \\
+/-47 \\
\text { NS }\end{array}$ & $\begin{array}{l}264 \\
0.3 \\
+/-45 \\
\text { NS }\end{array}$ \\
\hline
\end{tabular}

$\mathrm{d}=$ mean difference between repeated values of hand held refractor.

NS $=$ not significant

Table 2 Agreement between non-cycloplegic quick and normal mode Retinomax values

\begin{tabular}{|c|c|c|c|c|c|c|}
\hline & \multicolumn{2}{|c|}{ Sphere (D) } & \multicolumn{2}{|c|}{ Cylinder (D) } & \multicolumn{2}{|l|}{ Axis (\%) } \\
\hline & Right eye & Left eye & Right eye & Left eye & Right eye & Left eye \\
\hline $\begin{array}{l}\text { Number of pairs } \\
\mathrm{d} \\
95 \% \text { lim agreement } \\
\mathrm{p} \text { (paired } t \text { test) }\end{array}$ & $\begin{array}{l}93 \\
0.11 \\
+/-2.65 \\
\text { NS }\end{array}$ & $\begin{array}{l}93 \\
0.10 \\
+/-1.90 \\
\text { NS }\end{array}$ & $\begin{array}{l}93 \\
-0.07 \\
+/-0.80 \\
\text { NS }\end{array}$ & $\begin{array}{l}93 \\
-0.02 \\
+/-0.62 \\
\text { NS }\end{array}$ & $\begin{array}{l}73 \\
2.56 \\
+/-48 \\
\text { NS }\end{array}$ & $\begin{array}{l}79 \\
0.76 \\
+/-40.5 \\
\text { NS }\end{array}$ \\
\hline
\end{tabular}

$\mathrm{d}=$ mean difference of quick mode value minus normal mode value. NS $=$ not significant
Table 3 Agreement between non-cycloplegic and cycloplegic Retinomax cylinder power

\begin{tabular}{lll}
\hline & \multicolumn{2}{l}{ Cylinder (dioptre) } \\
\cline { 2 - 3 } & Right eye & Left eye \\
\hline Number of pairs & 302 & 302 \\
$\mathrm{~d}$ & 0.16 & 0.19 \\
$\begin{array}{l}\text { 95\% lim agreement } \\
\mathrm{p} \text { (paired } t \text { test) }\end{array}$ & $\mathrm{d}+/-1.23$ & $\mathrm{~d}+/-1.22$ \\
\hline
\end{tabular}

$\mathrm{d}=$ mean difference of non-cycloplegic minus cycloplegic value. $\mathrm{S}=$ significant .

the consultation), we could not gather these refractive data for all the positive children.

Predictive values of our refractive screening were calculated for three different thresholds of manifest astigmatism $(\geqslant 1.5, \geqslant 1.75$, and $\geqslant 2$ D) considering as a true positive case an astigmatism $\geqslant 2 \mathrm{D}$ under cycloplegia. These predictive values were estimated in the 302 cases having cycloplegic refraction measured by Retinomax and in the 88 cases having cycloplegic refraction performed by retinoscopy or an on table refractor.

\section{Results}

Figure 1 shows the age distribution in months of the 1205 screened children, of the 302 children refracted under cycloplegia by the hand held refractor, and of the 88 children refracted under cycloplegia by retinoscopy or on table refractor.

Table 1 shows the mean difference of refractive findings and $95 \%$ limits of agreement of the 299 pairs of repeated manifest measurements by Retinomax. Paired $t$ test was applied to test the null hypothesis of a mean difference equal to zero.

Table 2 shows the same statistical tests applied to the 93 pairs of manifest refraction performed under the quick and the normal mode of the Retinomax.

Table 3 shows the same statistical tests applied to non-cycloplegic versus cycloplegic Retinomax cylinder values in the same subject.

Tables 4 and 5 show the rates of sensitivity, specificity, positive, and negative predictive values of the screening for three different thresholds of manifest astigmatism ( $\geqslant 1.5$, $\geqslant 1.75, \geqslant 2 \mathrm{D}$ ). True positive case is defined by a cycloplegic cylinder value $\geqslant 2 \mathrm{D}$. Table 4 displays the 302 cases who were refracted under cycloplegia by the hand held refractor. Table 5 includes the 88 cases who were refracted under cycloplegia by retinoscopy or on table refractor.

\section{Discussion}

Twenty per cent of children are screened positive for refractive anomalies and/or squint. This figure is approximately twice that found in the literature..$^{511}$ The reason is that our screening is made on an appointment basis and not on a captive population (for example, screening children at school). It follows that a selection bias was present in the population we screened: among others, we selected many children with a family history of strabismus or amblyopia and also children having a visual anomaly suspected by their parents or paediatrician. 
Table 4 Performances of the non-cycloplegic screening for three different thresholds of manifest astigmatism (true positive case if Retinomax cycloplegic cylinder value $\geqslant 2$ D)

\begin{tabular}{lllllll}
\hline Manifest cylinder & $\begin{array}{l}\text { Positive test } \\
n(\%)\end{array}$ & $\begin{array}{l}\text { Negative test } \\
n(\%)\end{array}$ & $\begin{array}{l}\text { Sensitivity } \\
(\%)\end{array}$ & $\begin{array}{l}\text { Specificity } \\
(\%)\end{array}$ & $\begin{array}{l}\text { PPV } \\
(\%)\end{array}$ & $\begin{array}{l}\text { NPV } \\
(\%)\end{array}$ \\
\hline $\begin{array}{l}\text { 2 D } \\
\quad \text { Right eye }\end{array}$ & $32(11)$ & $270(89)$ & 51 & 98 & 81 & 91 \\
$\quad \begin{array}{l}\text { Left eye } \\
\text { 1.75 D }\end{array}$ & $38(13)$ & $264(87)$ & 54 & 98 & 84 & 90 \\
$\quad$ Right eye & $42(14)$ & $260(86)$ & 59 & 95 & 71 & 92 \\
$\quad \begin{array}{l}\text { Left eye } \\
\text { 1.5 D }\end{array}$ & $60(20)$ & $242(80)$ & 80 & 95 & 78 & 95 \\
$\quad$ Right eye & $62(20)$ & $240(80)$ & 71 & 90 & 58 & 94 \\
$\quad$ Left eye & $70(23)$ & $232(77)$ & 84 & 92 & 71 & 96 \\
\hline
\end{tabular}

$\mathrm{PPV}=$ positive predictive value

$\mathrm{NPV}=$ negative predictive value.

Table 5 Performances of the non-cycloplegic screening for three different thresholds of manifest astigmatism (true positive case if cycloplegic cylinder value by retinoscopy or on table refractor $\geqslant 2$ D)

\begin{tabular}{lllllll}
\hline Manifest cylinder & $\begin{array}{l}\text { Positive test } \\
n(\%)\end{array}$ & $\begin{array}{l}\text { Negative test } \\
n(\%)\end{array}$ & $\begin{array}{l}\text { Sensitivity } \\
(\%)\end{array}$ & $\begin{array}{l}\text { Specificity } \\
(\%)\end{array}$ & $\begin{array}{l}\text { PPV } \\
(\%)\end{array}$ & $\begin{array}{l}\text { NPV } \\
(\%)\end{array}$ \\
\hline $\begin{array}{l}\text { 2 D D } \\
\quad \text { Right eye }\end{array}$ & $20(23)$ & $68(77)$ & 52 & 95 & 85 & 76 \\
$\quad \begin{array}{l}\text { Left eye } \\
\text { 1.75 D }\end{array}$ & $25(29)$ & $62(71)$ & 65 & 90 & 76 & 87 \\
$\quad \begin{array}{l}\text { Right eye } \\
\text { Left eye }\end{array}$ & $23(26)$ & $65(74)$ & 58 & 93 & 83 & 78 \\
$\begin{array}{l}\text { 1.5 D } \\
\text { Right eye }\end{array}$ & $35(40)$ & $52(60)$ & 83 & 81 & 69 & 90 \\
$\quad$ & $31(35)$ & $57(65)$ & 82 & 93 & 87 & 89 \\
\hline
\end{tabular}

$\mathrm{PPV}=$ positive predictive value.

$\mathrm{NPV}=$ negative predictive value

The relative proportion of positive $(43 \%)$ and negative $(57 \%)$ results among the 302 children controlled under cycloplegia is different from the one of the screening $(20 \%$ versus $80 \%$ ). In our opinion, the reason is that the parents were more inclined to accept the cycloplegia for their child if it was to confirm an anomaly.

The age distribution in the 1205 screened children and in the 302 children also refracted under cycloplegia by the hand held refractor is similar, showing a good breakdown of the population by age groups. Less than $15 \%$ of the children did not have the intended screening age and we deemed it unnecessary to discard them for the statistical analysis.

The distribution of age of the 88 children screened positive and refracted under cycloplegia by the ophthalmologist to whom the child was referred shows a definite trend towards higher ages. As we decided in this study to discard the refractive feedback that took place more than 6 months after the screening, the delay between the screening and the consultation cannot explain this difference. We think that the main reason is the following: the ophthalmologist was reluctant to send us a dated and signed form specifying the cycloplegic refraction of the child if he was not confident in his own measurement of the child's refraction. Therefore, most of the refractive feedback that we received concerned children of 2 years and over who were refracted by an on table refractor (78 children) rather than by retinoscopy (10 children).

There is no significant difference between non-cycloplegic repeated measurements of cylinder and axis with Retinomax. The 95\% limits of agreement between two repeated cylinder measurements reach levels slightly less than $\pm 1 \mathrm{D}$. This is comparable with the agreement between repeated measurements along one meridian by non-cycloplegic autorefraction $(-0.72$ to $0.71 \mathrm{D})$ and by cycloplegic retinoscopy $(-0.87$ to $1.02 \mathrm{D}) .^{12}$

The $95 \%$ limits of agreement for the axis are $\pm 46^{\circ}$, which conforms with the literature: Berman et $a l^{13}$ found it to be $\mathrm{d} \pm 33^{\circ}$ in repeated non-cycloplegic retinoscopy and $\mathrm{d} \pm 65^{\circ}$ in repeated manifest autorefraction (CanonR-1). McBrien and Millodot ${ }^{14}$ found $\mathrm{d} \pm 20^{\circ}$ with the same Canon autorefractor in manifest conditions. Wood et $a l^{15}$ found $\mathrm{d} \pm 40^{\circ}$ with the Nidek autorefractor in manifest conditions.

The comparison of non-cycloplegic measurements in the quick and normal mode give similar results: no significant difference and $95 \%$ limits of agreement around $\pm 0.75 \mathrm{D}$. This confirms our previous study ${ }^{7}$ concerning the amount of sphere in hyperopic children: no difference is seen between the quick and the normal modes in minimising accommodation. We therefore suggest choosing the quick mode for screening children of this age, since measurements in this mode are much easier to obtain and nearly always successful in our test.

The mean difference between noncycloplegic and cycloplegic cylinder values measured by Retinomax reaches $0.17 \mathrm{D}$ and is statistically significant. This means that the value of the cycloplegic cylinder is generally higher than the non-cycloplegic one (all our cylinders are negative). As already suggested by Rubin and Harris, ${ }^{16}$ this could imply that the accommodative change in a human eye is not entirely spherical in nature but may include an additional cylindrical component. This difference of $0.17 \mathrm{D}$ is, however, not clinically important from a screening point of view.

Several concerned ophthalmologists do not prescribe glasses in children of 12 months of age if an astigmatism with coincident axes is below $2 \mathrm{D} .{ }^{17}$ We chose therefore a value of $2 \mathrm{D}$ or more of astigmatism under cycloplegic condition as true positive case to establish the sensitivity, specificity, and predictive values of the screening.

In our opinion, Table 4 gives a more accurate idea of the overall sensitivity and specificity rates of our screening than Table 5: the sample is larger (302 children versus 88 ), the age distribution is comparable with the one of the screened population (Fig 1), and the refraction is better controlled (all measurements were made the same day, by the same operators, with the same refractor, and using the same cycloplegic protocol). The results of both tables are however rather similar. The threshold of manifest astigmatism $\geqslant 2 \mathrm{D}$ gives the best figures regarding specificity and positive predictive value. The thresholds of $\geqslant 1.75 \mathrm{D}$ and $\geqslant 1.5 \mathrm{D}$ give a better combination of sensitivity and specificity.

Although a high threshold of abnormal astigmatism diminishes the sensitivity of the screening, it improves its specificity. To validate our visual screening and as astigmatism is not a severely disabling eye condition, we preferred a highly specific test to avoid overreferrals and to have a good positive predictive value. ${ }^{18}$ 
Therefore, we decided to keep the threshold of $2 \mathrm{D}$ for the ongoing screening.

To conclude, manifest refractive screening with Retinomax diagnoses abnormal astigmatism ( $\geqslant 2 \mathrm{D}$ ) with $51 \%$ to $84 \%$ sensitivity rates and $98 \%$ to $90 \%$ specificity rates, depending on the chosen threshold of manifest astigmatism. If $2 \mathrm{D}$ of manifest astigmatism is considered for positive test, the positive predictive value of the screening reaches $81-84 \%$ and the negative predictive value $91-90 \%$ (right eyeleft eye). As the quick mode of measurement is more feasible in children and as we did not establish any significant difference between the quick mode and the normal mode in measuring manifest refraction, we also suggest choosing this mode of measurement for screening very young children.

This study has been funded by "Les Amis des Aveugles" ASBL, rue de la barrière, 37-39, 7011 Ghlin

The authors would like to thank Moktar Essarhdaoui, the main operator of the screening.

1 Saunders KJ. Early refractive development in humans. Surv Ophthamol 1995;40:207-16

2 Gwiazda J, Bauer J, Thorn F, et al. Meridional amblyopia does result from astigmatism in early childhood. Clin Vis Sci 1986;1:145-52.

3 Ingram RM, Walker C, Wilson JM, et al. Prediction of amblyopia and squint by means of refraction at age 1 year. Br F Ophthalmol 1986;70:12-15.

4 Sjöstrand J, Abrahamsson M. Risk factors in amblyopia. Eye 1990;4:787-93.
5 Atkinson J, Braddick O, Bobier B, et al. Two infant screening programmes: prediction and prevention or strabismus and amblyopia from videorefractive screening. Eye 1996; 10:189-98.

6 Friedburg D, Kloppel KP. Early spectacle correction of hypermetropia and astigmatism in childhood results in better development of visual acuity. Klin Monatsbl Augenheilkd 1996;209:21-4.

7 Cordonnier M, Dramaix M. Screening for abnormal levels of hyperopia in children: a non-cycloplegic method with a hand held refractor. Br f Ophthalmol 1998;82:1260-4.

8 Cordonnier M, Dramaix M, Kallay O, et al. How accurate is the hand-held refractor Retinomax ${ }^{\circledR}$ in measuring cycloplegic refraction: a further evaluation. Strabismus 998;6:133-42.

9 Banks MS. Infant refraction and accommodation. Int $O p h-$ thalmol Clin 1980;20:205-32.

10 Bland JM, Altman DG. Statistical methods for assessing agreement between two methods of clinical assessment. Lancet 1986;1:307-10.

11 Preslan MW, Novak A. Baltimore vision screening project. Ophthalmology 1996;103:105-9.

12 Zadnik K, Mutti DO, Adams AJ. The repeatability of measurement of the ocular components. Invest Ophthalmol measurement of the ocular

13 Berman M, Nelson P, Caden B. Objective refraction: comparison of retinoscopy and automated techniques. $\mathrm{Am}$ f Optom Physiol Opt 1984;61:204-9.

$14 \mathrm{McBrien}$ NA, Millodot M. Clinical evaluation of the Canon autoref R-1. Am f Optom Physiol Opt 1985,62:786-92.

15 Wood ICJ, Papas E, Burghardt D, et al. A clinical evaluation of the Nidek autorefractor. Ophthalmic Physiol Opt 1984;4 169-78.

16 Rubin A, Harris WF. Refractive variation during autorefraction: multivariate distribution of refractive status. autorefraction: multivariate dist

17 Haase W, Friedburg D, Von Noorden GK, et al. Die refraktion im kindesalter als risikofaktor für die entwicklung von amblyopien und/oder strabismus. Klin Monatsbl Augenheilkd 1994;204:48-54.

18 Leske MC, Hawkins B. Screening: relationship to diagnosis and therapy. In: Duane TD, Jaeger EA, eds. Clinical ophthalmology. Philadelphia: Harper and Row, 1994;5:3. 